\title{
工 Wism

\section{A escrita-currículo da perspectiva cultural da Educação Física: por que os professores fazem o que fazem?}

The writing-curriculum of the cultural perspective of Physical Education: why teachers does what do?

La escritura-currículo de la perspectiva cultural de la Educación Física: ¿por qué los profesores hacen lo que hacen?

\section{* Pedro Xavier Russo Bonetto}

Mestre pela Faculdade de Educação da Universidade de São Paulo, São Paulo, São Paulo, Brasil. psorpedro@yahoo.com.br

** Marcos Garcia Neira

Professor Titular da Faculdade de Educação da Universidade de São Paulo, São Paulo, São Paulo, Brasil. mgneira@usp.br

Recebido: 08 de Julho de 2018

Aprovado: 13 de novembro de 2018

\section{RESUMO}

$\mathrm{Na}$ esteira do exemplo de Deleuze-professor, o presente artigo problematiza os elementos a partir dos quais 10 docentes constroem o currículo cultural da Educação Física, ou seja, os aspectos didático-metodológicos que mobilizam e as forças que os atravessam quando pensam as atividades de ensino. Como forma de produção de dados, recorreu-se ao Diário de Bordo Digital e ao Grupo de Discussão. Nas análises realizadas mediante o confronto com o referencial deleuze-guattariano, que a "escritacurrículo" é produzida no entrecruzar de infinitas linhas, algumas molares (as leis educacionais, as regras e normas do regimento escolar, o Projeto Político Pedagógico), outras moleculares (a cultura dos alunos, seus desejos, atitudes, falas, as disposições espaciais, temporais e os princípios pedagógicos) e, por fim, as linhas de fuga, que, sendo efêmeras, passam pela "escrita-currículo" como acontecimentos e agenciamentos inesperados, disruptivos e criadores. Atentos e desejando tais agenciamentos, os professores e professoras, sensíveis às linhas de força flexíveis, fazem da "escrita-currículo" um acontecimento sempre traduzido, singular, diferente, especial, raro e único.

Palavras-chave: Educação física; Currículo; Deleuze. 


\section{WEM Ellubahá}

DOI: $10.5902 / 1984644433532$

\section{ABSTRACT}

In the wake of the Deleuze-teacher example, this article want to problematize on the way from which elements we construct our curriculum. 10 teachers (of Physical Education) that daily seek to put the cultural curriculum in action, we do like? Why? From which didactic-methodological elements do we develop our classes? What forces cross us when we think of teaching activities? As a form of data production, we employ a Digital Diary and the Discussion Group. To what we can observe, the "writingcurriculum" is produced in the intertwining of infinite lines, some molars (hard), such as: educational laws, rules and regulations of the school regulations, the Pedagogical Political Project; other molecular (flexible): the culture of the students, their desires, attitudes, speech, spatial arrangements, timing and pedagogical principles; and finally, by lines of flight, which as ephemeral not territorialize in pedagogical statements, pass through "writing-curriculum" as unexpected events and assemblages, disruptive and creators. Attentive and desiring such assemblages, teachers sensitive to flexible lines of force, make "writing-curriculum" an event always translated, singular, different, special, rare and unique.

Keywords: Physical education; Curriculum; Deleuze.

\section{RESUMO}

En el marco del ejemplo de Deleuze-profesor, el presente artículo problematiza los elementos a partir de los cuales 10 docentes construyen el currículo cultural de la Educación Física, o sea, los aspectos didáctico-metodológicos que movilizan y las fuerzas que los atravesan cuando piensan las actividades de educación. Como forma de producción de datos, se recurrió al Diario de Bordo Digital y al Grupo de discusión. En los análisis realizados mediante la confrontación con el referencial deleuzeguattariano, que la "escritura-currículo" es producida en el entrecruzar de infinitas líneas, algunas molares (las leyes educativas, las reglas y normas del regimiento escolar, el Proyecto Político Pedagógico), otras (la cultura de los alumnos, sus deseos, actitudes, discursos, las disposiciones espaciales, temporales y los principios pedagógicos) y, por fin, las líneas de fuga, que, siendo efímeras, pasan por la "escritura-currículo" como acontecimientos y agitación inesperados, disruptivos y creadores. En el caso de los profesores y profesoras, sensibles a las líneas de fuerza flexibles, hacen de la "escritura-currículo" un acontecimiento siempre traducido, singular, diferente, especial, raro y único.

Palavras-chave: Educación física; plan de estudios; Deleuze.

\section{Introdução}




\section{ON WFH ollubará}

DOI: $10.5902 / 1984644433532$

França, 1968. Juntos, estudantes, inspirados no marxismo e nas primeiras obras críticas de Pierre Bourdieu e Jean-Claude Passeron, operários e demais trabalhadores assalariados, ocupam escolas, universidades e fábricas. Enquanto, os estudantes cobravam a abertura e revisão do modelo escolar, sobretudo o universitário, considerado antiquado, excludente e reprodutor das estruturas de classe da sociedade, os movimentos de greve, barricadas, assembleias e das chamadas "comissões de reflexão" fizeram emergir um forte ideário revolucionário. Foram criadas universidades e modalidades de ensino superior mais abertas e acessíveis à classe trabalhadora, àqueles não possuíam o bacharelado ${ }^{1} \mathrm{e}$ aos imigrantes. Foi isso o que fez o Centro Universitário Experimental de Vincennes, hoje Universidade de Paris VIII.

Neste período agitado e tenso, no Departamento de Filosofia, Michel Foucault, Jacques Lacan, Michel Serres, François Châtelet, Etienne Balibar e Gilles Deleuze viveram o que ficou conhecido como "individualismo pedagógico". Ou seja, cada professor, independentemente do seu estatuto, podia ensinar o que bem desejava. Caberia a ele apenas conseguir seu público, uma vez que os estudantes organizavam livremente o seu percurso curricular. Se alguns professores não suportaram a desordem de Vincennes, dentre eles Foucault, Balibar, Serres e Lacan, a ponto de deixarem a instituição, outros, como Gilles Deleuze, entenderam que este seria o local propício para manifestar seu pensamento.

Livre para lecionar ao seu modo, o filósofo adotou o formato de "aulas magnas". Somente ele falava, não abria momentos para a participação dos estudantes e tinha horror a discussões. Sobre as perguntas, jamais às respondia pois, para ele, o objetivo de quem perguntava não era sanar uma dúvida, mas sair-se bem. Como parte de sua filosofia, Gilles Deleuze acreditava no "efeito retardado" de uma pergunta, ou seja, no fato de que não se entende a questão no mesmo momento, na mesma hora. Era preciso tempo, reflexão, sem nada a ser discutido. Em vez disso, era importante sentir, contagiar-se afirmativamente ou simplesmente recusar.

E assim foi de 1969 a 1987. Em salas ocupadas por estudantes de diferentes

\footnotetext{
${ }^{1}$ Exames nacionais realizados no final dos estudos do liceu, etapa da escolarização correspondente ao nosso Ensino Médio.
} 


\section{W WEM \\ 15SN: 1984-6444

DOI: $10.5902 / 1984644433532$

cursos (música, arte, cinema e outros tantos que, às vezes, nem matrícula possuíam), Deleuze desenvolvia uma perspectiva filosófica de uso artístico, para além da academia e das fronteiras do pensamento disciplinar ${ }^{2}$. Mas, por que agia desse modo?

Com base nos próprios ensinamentos da filosofia deleuze-guattariana, é possível afirmar que Deleuze-professor lecionava dessa forma porque era atravessado por certas forças $\left.{ }^{3}: 1\right)$ algumas possivelmente relacionadas com o contexto social francês da época - França pós-1968, subversão, crítica social e ao academicismo, rebeldia, desejo de participação política e preeminência do aspecto político sobre o intelectual; 2) talvez, por características da instituição - flexibilidade de organização, abertura a pessoas de diversas origens e anseios, curso sem reconhecimento oficial; 3) por forças de sua concepção filosófica - aula enquanto uma música que não pode ser interrompida, aula que necessita ser ensaiada, fruto de inspiração, valorização da relação assimétrica entre mestre e discípulos, características performáticas, sem perguntas, sentir ao invés de compreender; e 4) por motivo das suas próprias características físicas: voz calma, serenidade, carisma, busca do afeto e fragilidade.

Inspirados em Deleuze-professor, o presente artigo problematiza o modo, ou mais especificamente, os elementos, a partir dos quais 10 docentes constroem o currículo cultural da Educação Física, os elementos didático-metodológicos que mobilizam e as forças que os atravessam quando pensam as atividades de ensino. Em suma, pretendemos suscitar o seguinte pensamento: por que fazem desse modo? Esquivando-nos das respostas universais e generalizantes, nos propomos produzir uma breve análise das forças ${ }^{4}$ que influenciam e resultam no fazer curricular.

Baseado na teorização pós-crítica e inspirado em conceitos e orientações teórico-metodológicas dos Estudos Culturais, multiculturalismo crítico, póscolonialismo, pós-estruturalismo, teoria Queer, estudos feministas e étnico-raciais, o

\footnotetext{
2 Os contextos políticos e educacionais descritos, bem como as particularidades pedagógicas das aulas ministradas por Gilles Deleuze no Departamento de Filosofia do Centro Universitário Experimental de Vincennes, foram extraídos do artigo Deleuze pedagogo, de Charles Soulié (2015).

${ }^{3}$ Nessa perspectiva, força é algo de certo modo incorporal, incorpóreo, mas atribuída ao corpo. É no corpo que se nota o efeito de uma força. A força é o que confere movimento ao corpo.

${ }^{4}$ Por conta da complexidade, ou melhor, da quantidade de multiplicidades envolvidas e do movimento contínuo que empreendem, consideramos impossível mapear todas as forças que se combinam nos agenciamentos que compõem a "escrita-currículo".
} 


\section{W WEM

DOI: $10.5902 / 1984644433532$

currículo cultural da Educação Física, também chamado de pós-crítico ou culturalmente orientado emergiu no século XXI, a partir de experiências realizadas no seio do Grupo de Pesquisas em Educação Física escolar da Feusp ${ }^{5}$. Como função social, deseja ampliar e aprofundar o repertório que os estudantes possuem em relação às práticas corporais, ressignificando o que é produzido no âmbito da cultura, reconhecendo e desconstruindo as relações de poder que se engendram e produzem as danças, lutas, esportes, brincadeiras e ginásticas tal como as conhecemos.

Enquanto artefatos culturais, as práticas corporais veiculam significados e representações de mundo e sociedade. Por esse motivo, o currículo cultural se propõe a tematizá-las partindo da produção cultural dos diversos grupos que coabitam a sociedade. $\mathrm{O}$ intuito é a formação de cidadãos capazes de compreender, analisar e reconhecer, mesmo que parte das relações de poder (de classe, gênero, local de moradia, habilidade, características físicas, deficiências e tantas outras) que se engendram nas manifestações da gestualidade sistematizada, produzindo, por vezes, efeitos negativos entre as pessoas que as acessam, entre eles, a discriminação, preconceito e exclusão. (NEIRA, 2011)

Em relação aos aspectos didático-metodológicos, ganham evidência certos procedimentos de ensino, dentre eles: mapeamento, leitura, vivência, ressignificação, aprofundamento, ampliação, registro e avaliação. No tocante aos princípios curriculares, destacam-se: reconhecimento da cultura corporal dos estudantes, articulação com o projeto da escola, justiça curricular, descolonização do currículo, evitamento do daltonismo cultural e ancoragem social dos conhecimentos. Abarcando estes elementos, a ação didática característica pode ser entendida a partir do conceito de "escrita-currículo". Esta, se coloca, tal como afirmam Neira e Nunes (2009), como uma alternativa à homogeneização e ao engessamento que as pedagogias monoculturais insistentemente vêm repetindo na Educação Física.

\footnotetext{
${ }^{5}$ Uma descrição detalhada do processo de construção dessa proposta pode ser acessada no recente Educação Física cultural: inspiração e prática pedagógica, de Marcos Garcia Neira (2018).
} 


\section{T Wsm

DOI: $10.5902 / 1984644433532$

\section{Ferramentas conceituais: agenciamento, linhas de força e acontecimento}

$\mathrm{Na}$ perspectiva filosófica antirrealista e irracionalista deleuze-guattariana, as ações, pensamentos e tudo aquilo que produzimos ou conquistamos, incluindo o currículo escolar, não são meros frutos de ideias ou esforços. Radicalizando o ponto de partida, afirmamos que não há nada original, novo e criativo que não tenha parentesco nem proximidade com aquilo que já existe. O pressuposto deleuziano é que o novo e o diferente são produzidos na repetição do mesmo, uma pequena variação deste, que se potencializa em meio a outras diversas forças que se engendram na constituição das coisas. Agenciamento! Eis o conceito que ajuda a compreender como isso acontece.

[...] estamos em uma relação de agenciamento todas as vezes em que pudermos identificar e descrever o acoplamento de um conjunto de relações materiais e de um regime de signos correspondente. Em outras palavras, um agenciamento é uma multiplicidade que comporta muitos termos heterogêneos e que estabelece ligações, relações entre eles, através das idades, sexos, reinos, de naturezas diferentes. Assim, a única unidade do agenciamento é o co-funcionamento: é a simbiose, uma 'simpatia' (DELEUZE; PARNET, 1998, p. 84).

De forma abreviada, é possível dizer que o agenciamento é o encontro entre os enunciados, as coisas e as pessoas. O agenciamento é uma ocasião, especificamente produzida em uma mistura de forças, o choque de vetores, um emaranhado de intensidades que pode, por exemplo, ser entre uma pessoa e um livro, uma pessoa e um acontecimento e entre duas ou mais pessoas.

No campo educacional, a noção de agenciamento é potencialmente importante para pensar, por exemplo, porque que professores que estudaram na mesma instituição, leram as mesmas coisas, se baseiam no mesmo referencial teórico, enunciam interpretações e práticas pedagógicas absolutamente diferentes entre si. É um conceito que, de certo modo, nos tira do protagonismo da ação e mostra o quão, muitas vezes, somos apenas passageiros nestes encontros.

(...) a maneira como o indivíduo investe e participa da reprodução desses agenciamentos sociais depende de agenciamentos nos quais ele próprio é apanhado, seja porque, limitando-se a efetuar as formas socialmente disponíveis, a modelar sua existência segundo os códigos em vigor, ele aí introduz sua pequena irregularidade, seja porque procede à elaboração involuntária e tateante de agenciamentos próprios que 'decodificam' ou 


\section{F WFM

DOI: $10.5902 / 1984644433532$

'fazem fugir' (entre os quais é preciso incluir os agenciamentos artísticos). Todo agenciamento, uma vez que remete em última instância ao campo de desejo sobre o qual se constitui, é afetado por um certo desequilíbrio. (ZOURABICHVILI, 2004, p. 9)

Por conta da complexidade de forças e das suas diferentes intensidades no centro desse encontro, um agenciamento pode tanto ser imprevisível, disruptivo e absolutamente revolucionário, quanto duro, autoritário, fixador de códigos, estruturas e classificações. Estamos aqui, tratando das forças, ou linhas, que compõem os agenciamentos. Deleuze e Guattari (1996) descrevem três tipos:

1) Linhas de segmentaridade dura: a) os segmentos dependem de máquinas binárias de classes sociais, de sexos, idades, raças, setores, subjetivações. Em outras palavras, é a linha que delimita, classifica, define fronteiras, fecha estruturas e as impõe como único modo de pensar; b) os segmentos implicam também dispositivos de poder bem diversos entre si, cada um fixando o código e o território do segmento correspondente. Tratam-se de agenciamentos de poder autoritários porque impõem a significância e a subjetivação como sua forma de expressão; c) todas as linhas de segmentaridade dura envolvem um certo plano que concerne, a um só tempo, as formas e seu desenvolvimento e os sujeitos e sua formação.

2) Linhas de segmentaridade molecular ou flexíveis: a) procedem por limiares, constituem devires, blocos de devir, marcam contínuos de intensidade, conjugações de fluxos. Segundo Deleuze e Parnet (1998, p. 101), promovem mutações a cada limiar e cada conjugação, "fazem correr, entre os segmentos, fluxos de desterritorialização que já não pertencem nem a um nem a outro"; b) Deleuze e Guattari (1997) afirmam que as linhas moleculares são do tipo "rizoma".

Ao mesmo tempo, temos linhas de segmentaridade bem mais flexíveis, de certa maneira moleculares. Não que sejam mais íntimas ou pessoais, pois elas atravessam tanto as sociedades, os grupos, quanto os indivíduos. Elas traçam pequenas modificações, fazem desvios, delineiam quedas ou impulsos: não são, entretanto, menos precisas; elas dirigem até mesmo processos irreversíveis. (DELEUZE; PARNET, 1998, p. 101).

3) Linhas de fuga não são, em um agenciamento, fenômenos de resistência ou de réplica tal como as demais linhas, mas picos de criação e de desterritorialização. Para Deleuze e Parnet (1998), as linhas de fuga são as mais estranhas, é como se alguma coisa nos levasse através dos segmentos, mas também através de nossos 


\section{Dism

DOI: $10.5902 / 1984644433532$

limiares, para um destino desconhecido, imprevisível, não preexistente. Para eles, são as linhas mais complicadas de todas, as mais tortuosas, de maior declive, são as linhas de gravidade ou celeridade. "Há linhas que não se reduzem ao trajeto de um ponto, e escapam da estrutura, linhas de fuga, devires, sem futuro nem passado, sem memória, que resistem à máquina binária”. (p. 22).

[...] tento explicar que as coisas, as pessoas, são compostas de linhas bastante diversas, e que elas não sabem, necessariamente, sobre qual linha delas mesmas elas estão, nem onde fazer passar a linha que estão traçando: em suma, há toda uma geografia nas pessoas, com linhas duras, linhas flexíveis, linhas de fuga etc. (DELEUZE; PARNET, 1998, p. 9).

Deleuze e Guattari (1997) explicam que três linhas nos compõem, cada qual com seus perigos. Não só as linhas duras que nos cortam e nos impõem as estrias de um espaço homogêneo, mas também as linhas moleculares, que já carregam seus microburacos negros e, por último, as linhas de fuga, que sempre ameaçam abandonar suas potencialidades criadoras para transformar-se em linhas de destruição.

Tendo em vista os conceitos de agenciamento e os tipos de linhas de força que constituem as coisas e produzem os pensamentos, podemos perguntar o que "acontece" e leva alguém a modificar o pensamento? Ou ainda, o que é isso que faz mudar, adaptar, fazer de outra forma? Resposta: o acontecimento!

Bianco (2005) descreve o acontecimento como contingente, porque de algum modo depende das ocasiões que o produz, e é exatamente este que força o pensamento.

A nova imagem do pensamento opõe-se à imagem dogmática do pensamento: acima de tudo, o pensamento não pressupõe um ato voluntário de fundação que eliminaria os pressupostos para iniciar do zero, já que o pensamento começa sempre pela diferença, au milieu, no meio de alguma coisa, por causa de alguma coisa que força o pensador a pensar: o acontecimento que faz sentido e que corta o escorrer linear do tempo. Aquilo que força o pensamento provoca um choque que faz com que cada faculdade saia de seus eixos, os quais coincidem com os limites do bom senso e do senso comum. (BIANCO, 2005, p. 1295)

As noções de agenciamento e acontecimento podem ser vistas como ferramentas conceituas para análise das questões que abrangem o "fazer" curricular da Educação Física. Na sequência, trataremos de contextualizar, ainda que de forma breve, os modos como vem sendo feito o ensino do componente na escola, ou melhor, 


\section{WEM Ellloahao}

DOI: $10.5902 / 1984644433532$

como o componente tem operado didática e metodologicamente desde o início do século passado até os dias atuais.

\section{A "escrita-currículo": um antimodelo}

Atribui-se à "escrita-currículo" um caráter aberto, não linear, nem tampouco baseado em sequências didáticas. Ao contrário, é a produção de experiências curriculares menos rígidas, inspiradas na participação ativa e crítica de professores e alunos que assumem a condição de "escritores" da experiência curricular. É uma relação de reciprocidade, de constante construção-reconstrução. Podem, como preferimos dizer na perspectiva pós-estruturalista, produzir diferentes experiências curriculares, onde o novo, o criativo, o imprevisto, é desejado e não evitado.

Voltando à guarida de Deleuze e Guattari, ressaltamos a "pedagogia do conceito", uma espécie de radiografia de um conceito filosófico através de uma análise das noções básicas que o compõem: a) historicidade; b) assinatura; c) planos ou campos de imanência; d) elementos ou componentes; e) multiplicidades; f) personagens conceituais; g) traços de intensidade e objetividade.

Escrita-currículo aparece em Neira e Nunes (2009), inaugurando a perspectiva pós-crítica no âmbito da Educação Física. Enquanto campo de imanência, o conceito atravessa o componente, em específico, na concepção culturalista defendida pelos autores. É certo que os campos se conectam, e quanto maior for o número de planos que sustentam um campo, maior a consistência e relevância do conceito, uma vez que, maior será a quantidade de problemas que ele se propõe a responder. Resumidamente, podemos mencionar a educação, filosofia da educação, teorias curriculares pós-críticas, Educação Física e currículo cultural como campos de imanência ladrilhados pela "escrita-currículo".

Considerada a importância dos elementos do conceito, não podemos deixar de decompô-lo (escrita + currículo), e destacar que cada componente também pode ser analisado separadamente, pois preserva vontades e traços intensos relacionados à objetividade do próprio composto "escrita-currículo".

Dias Souza (2007) afirma que a escrita não é para Deleuze [e Guattari] simples ficção, produção de entidades fictícias, personagens e situações. Tudo isso são os meios, mas não o fim ou o superior objetivo de escrever. Como as demais artes, ela 


\section{O Hsm \\ ISSN: 1984-6444 \\ elithahá}

DOI: $10.5902 / 1984644433532$

é vida, mas não no sentido de dar forma a uma matéria vivida, de recriar a vida real das pessoas como vida imaginária. É, pelo contrário, criar vida, inventar linhas de vida possíveis, abrir à vida novas possibilidades.

Ainda nesta dimensão, podemos incluir o gesto de escrever, uma vez que "Escrever é um fluxo entre outros, sem nenhum privilégio em relação aos demais, e que entra em relação de corrente, contracorrente, de redemoinho com outros fluxos, fluxos de merda, de esperma, de fala, de ação, de erotismo, de dinheiro, de política etc." (DELEUZE, 1992, p. 19).

Escrever é dobrar o Fora, como faz o navio com o mar. Fazer do pensamento uma experiência do Fora, escapar do senso comum, desestruturar o bom senso, entrar em contato com uma violência que nos tira da recognição e nos lança diante do acaso, abalando certezas e o bem-estar da verdade. Perder as referências conosco e com o mundo exterior, afastar-nos do princípio da realidade, romper com as referências cognitivas, promover uma ruptura com a doxa, colocar em dúvida o próprio pensamento, o Divino, o Verdadeiro, o Belo, o Bem. Escrever é criar, aligeirar e descarregar a vida, inventar novas possibilidades de vida, fazer nascer o que ainda não existe, ao invés de representar o que já está dado e admitido. (CORAZZA, 2006, p. 29-30).

Já o outro componente do conceito "escrita-currículo", trata-se do tão difundido, estudado e por vezes blasfemado, "currículo". As teorias pós-estruturalistas, o pensamento foucaultiano, deleuze-guattariano, derridiano, onde os discursos, enunciados e textos modelam o pensamento por meio de estruturas da linguagem, também atravessaram o campo dos estudos curriculares. Nesses prismas, o currículo é um dispositivo disciplinar em que se desenvolve um discurso pedagógico engendrado em contextos diversos. O currículo tem um foco textual, ou seja, é concebido como prática de significação. As narrativas contidas em cada currículo, explícita ou implicitamente, corporificam noções particulares sobre de pensamento, subjetividades e modos de vida. Elas dizem qual conhecimento é legitimo e qual é ilegítimo, quais formas de conhecer são válidas e quais não o são, o que é certo e o que é errado, o que é moral e o que é imoral, o que é belo e o que é feio, quais vozes são autorizadas e quais não são (SILVA, 1995).

Encerrando os elementos que vivem no conceito "escrita-currículo", não poderíamos ignorar o "hífen", que além de se fazer presente nessa expressão, vive tão intensamente na obra deleuze-guattariana.

Descrevendo o que chamou de filosofia da pontuação, Agambem (2000, p. 171) 


\title{
T usm Futbabुa
}

DOI: $10.5902 / 1984644433532$

explica: "é menos frequente salientar que os sinais de pontuação, por exemplo, o hífen, pode assumir uma função técnica: o hífen é, deste ponto de vista, o mais dialético dos sinais de pontuação na medida em que une apenas porque distingue, e vice-versa". No termo "escrita-currículo", representa a "dialética da unidade e da separação, ou seja, a junção dos sentidos em reciprocidade e coabitação" (p. 172). O hífen alude a um conceito central na filosofia deleuze-guattariana, o devir. Poderíamos pensar uma "escrita" em devir "currículo" e o "currículo" em devir "escrita". Ambos os elementos, não deixam de ser o que são, muito menos passam a ser o outro, isso porque não se abandona o que se é para devir outra coisa, o devir não tem a dimensão de imitação ou identificação, mas uma forma de viver e de sentir numa conjunção de fluxos, por exemplo, a escrita passa a ser uma atividade pedagógica, enquanto o currículo, passa a ser uma composição artística e vice-versa.

De acordo com Deleuze e Guattari (2010), cada conceito também se remete a outros conceitos, não somente em sua história, mas em seu devir ou suas conexões presentes. Outros conceitos múltiplos compõem o mesmo problema da "escritacurrículo": "artistagem" (CORAZZA, 2006, 2011, 2012a), "didáticArtista" (CORAZZA, 2013) ou, ainda, "currículo-artistado" e "escrita-artista" (CORAZZA, 2006). Outro mais, criado por Neira (2007) e aproveitado por Neira e Nunes (2009) para descrever as potencialidades e características de uma "escrita-currículo" é "metáfora da capoeira".

\begin{abstract}
A capoeira, aqui utilizada com sua flexibilidade improvisadora e resistência aos métodos de ensino e treinamento positivistas, não é só uma manifestação lúdica, é também a forma de enfocar a vida. O capoeirista no seu improviso, atua tanto individualmente, como em harmonia com o seu adversário e o cosmos. É a sua individualidade que cataliza a tensão criativa do grupo, que canta e batuca mais forte, estimulando-o a realizar movimentos novos e nunca imaginados. Quando a "metáfora da capoeira" se introduz como princípio curricular, tanto os estudantes afrodescendentes quanto os pertencentes a outros grupos étnicos inserem-se nos modos africanos de ver e ser (NEIRA, 2007, p. 198).
\end{abstract}

A partir do conceito "escrita-currículo" aqui radiografado, pedagogizado, conceitualizado, e de suas multiplicidades podemos subtrair a imagem de, no mínimo, três personagens conceituais que nos ajudam a dar-lhe consistência: o escritor, o artista e o capoeirista.

Conforme Paulo-Benatte (2012), o devir do escritor não pode ser confundido com a figura historicamente construída do autor. "O autor, como mostrou Michel Foucault, 


\section{F WFH Ellloahá}

DOI: $10.5902 / 1984644433532$

é uma invenção recente, um dispositivo de controle de uma nova ordem do discurso, e que anuncia o sistema literário da modernidade". Já o escritor não é propriamente um sujeito, é antes disso, um inventor de agenciamentos, um "contrabandista das multiplicidades" (PAULO-BENATTE, 2012, p. 92).

O artista, para Deleuze (2003), desenvolve um trabalho interpretativo ou criativo. É justamente por meio do desdobramento dos diferentes tipos de signos que ele interpreta e cria que o artista vai, pouco a pouco, desdobrando a si próprio, isto é, se constituindo, descobrindo, redescobrindo ou inventando as verdades que se encontram implicadas em seu próprio devir ou trajetória de vida.

Por fim, o terceiro personagem que se remete ao último múltiplo abordado, a "metáfora da capoeira", é o "capoeirista". De acordo com Neira (2011), o capoeirista não joga com base em uma sequência pré-estabelecida e memorizada, os golpes surgem como resposta à gestualidade do oponente, o que faz do bom capoeirista um leitor atento do texto produzido pelo seu adversário. De quando em vez, o capoeirista se antecipa ao adversário e, prevendo seus golpes, o surpreende. A didática inspirada na capoeira consegue avançar sobre antigas crenças e reorganizar a abordagem dos temas a partir dos posicionamentos emitidos pelos estudantes.

Todo conceito remete a um problema, a problemas sem os quais não teria sentido, e que só podem ser isolados ou compreendidos na medida de sua solução. Um conceito tem sempre a verdade que lhe advém em função das condições de sua criação, além disso, o conceito tem uma objetividade que se adquire como um conhecimento certo, e não a objetividade que supõe uma verdade reconhecida como preexistente ou já lá. O conceito diz o acontecimento, não a essência ou a coisa.

Como vemos, a intensidade do conceito está na reconfiguração de um dos seus elementos, o currículo, pois, de maneira bastante desrruptiva, posiciona a educação no interstício da filosofia e da arte: currículo (aprender conteúdos, conhecimentos, portanto, conceitos) + escrita (arte, subjetividade, porvir, devir). No âmbito da Educação Física escolar, o conceito "escrita-currículo", "se coloca como alternativa à homogeneização, às representações e a fixação de signos da cultura dominante" (NEIRA; NUNES, 2009, p. 228).

A 'escrita-currículo', tal qual a 'escrita-artista', encontra-se em fluxo constante. Nela não há distinção entre teoria e prática. A teoria é tecida sobre a prática 


\section{T usm \\ ISSN: 1984-6444

DOI: $10.5902 / 1984644433532$

educacional. Todo conhecimento delineado é interpretativo, parcial e processual. Vive um devir duradouro continuamente modificado. O que se apresenta, portanto, longe de ser uma norma, é um convite, como bem diz Corazza, para que os professores e professoras deem prosseguimento à escrita-currículo que se anuncia. (NEIRA; NUNES, 2009, p. 227).

Entre objetividades e intensidades, vimos que o conceito procura abalar as práticas pedagógicas prescritas, fixas, rígidas, tradicionais, tecnicistas, procedimentais, acríticas, homogeneizantes, moralizantes, deterministas, sequenciais. O desejo é complexo: subverter a lógica moderna e hegemônica de se fazer educação, agindo por rupturas e por experimentações, substituindo o velho pelo novo, sem que este também se torne, apenas, um novo modelo. Ao contrário, é uma proposta contra qualquer elemento prescritivo, contra qualquer ordem ou sequência. Não é um modelo a ser seguido, mas um antimodelo.

\section{Dispositivos Metodológicos}

Entendemos que os "meios de produção de dados" de uma pesquisa não são meros instrumentos ou ferramentas, mas sim, dispositivos. De acordo com Deleuze (1990), um dispositivo é como uma espécie de novelo ou meada, um conjunto multilinear. É composto por linhas de naturezas variadas, que não abarcam nem delimitam sistemas homogêneos por sua própria conta (o objeto, o sujeito, a linguagem), mas seguem direções diferentes, formam processos sempre em desequilíbrio, tanto se aproximam como se afastam umas das outras. Os dispositivos podem ser entendidos como máquinas de fazer ver e de fazer falar que combinam campos de saber distintos, redes de discursos, relações de poder e modos de subjetivação, isto é, de produção de sujeitos.

O primeiro dispositivo metodológico empregado foi a criação de uma plataforma na internet denominada Diário de Bordo Digital $(\mathrm{DBD})^{6}$, possibilitando o registro dos locais em que aconteceram as aulas, as atividades pedagógicas, o período de duração das experiências curriculares e, até mesmo, questões mais subjetivas e complexas que permitiram inferir como se dá a "escrita-currículo" e a relação dos professores com os campos teóricos que inspiram o currículo cultural. Nesta etapa

\footnotetext{
${ }^{6}$ Finalizada a pesquisa o dispositivo foi disponibilizado ao público para utilização gratuita http://www.gpef.fe.usp.br/diario/admin/login/login.php. Acesso em 08/07/2018.
} 


\section{F WFH Ellloahao}

DOI: $10.5902 / 1984644433532$

participaram 8 professores.

Buscando entretecer os registros e falas, além de garantir que suas vozes, opiniões, impressões e pensamentos não se limitassem à estrutura de um DBD, realizamos um Grupo de Discussão (GD) com 7 docentes. Callejo Gallego (2001) considera que tal dispositivo, em sua gênese, é a produção de um diálogo, porém, em seu resultado, é um discurso. Tal distinção encontra sentido ao considerarmos o discurso uma construção a partir das análises do grupo. Ibáñez (2003; 2010) descreve que o grupo em si já consiste em uma máquina de produção de discurso. Gutierrez Brito (2008), Weller (2006) e Barbour (2009) entendem que a discussão, efetivamente, não tem como objetivo a busca de consenso entre os participantes. O importante é produzir um grande leque de opiniões, com pontos de vistas que podem ser debatidos por vários integrantes do grupo, aprofundando as questões.

O terceiro e último dispositivo foi a recolha e análise de 6 relatos de experiência. A ideia surgiu após 4 participantes do GD terem afirmado que dispunham de registros das tematizações de brincadeiras populares. Uma vez que os docentes do GD se conheciam e isso poderia ser a razão da aproximação de suas práticas, solicitamos a um professor de outro Estado (Paraná) que afirma atuar segundo os pressupostos do currículo cultural que nos enviasse 2 narrativas sobre as mesmas práticas corporais.

\section{"Escrita-currículo": o que ela está sendo...}

O confronto da perspectiva filosófica deleuze-guattariana com os registros disponíveis no DBD e a transcrição das conversas do GD, autoriza a dizer que tanto os procedimentos didáticos do currículo cultural da Educação Física (mapeamento, leitura, vivência, ressignificação, ampliação, aprofundamento, registro e avaliação), quanto seus princípios (reconhecimento da cultura corporal, articulação com o projeto da escola, justiça curricular, descolonização do currículo, ancoragem social dos conhecimentos e evitamento do daltonismo cultural) têm cumprido a função de palavras de ordem constituintes dos enunciados pedagógicos da proposta.

Analisando como os professores participantes do estudo vêm produzindo a "escrita-currículo", percebem-se vetores que se entrecruzam e atravessam. Embora nem sempre explícitos, descritos pela literatura ou visíveis no cotidiano escolar, tais 


\title{
U usm elithahá
}

DOI: $10.5902 / 1984644433532$

elementos estão continuamente passando pela escrita curricular, influenciando-a, tal como linhas de força descritas por Deleuze e Guattari. Nesse caso, o professor, os alunos, a infraestrutura da instituição, o clima, os materiais pedagógicos disponíveis, etc., configuram vetores que, em choque, se agenciam e produzem uma dada "escritacurrículo".

Tomando os elementos que constituem a "escrita-currículo", observamos que os procedimentos de ensino do currículo cultural têm se territorializado na "escritacurrículo" de maneira bastante forte. Pois, por mais que apresentem certas variações, suas aparições ocorrem de forma regular, ordenada e bem definida.

\begin{abstract}
Professor 1: Eu acho que o que se aproxima. Na maioria, são, no começo todos pedem descrições né? Ou pedem para os estudantes relatarem o que sabem sobre o tema, ou sobre a manifestação cultural estudada. Na maioria tem uma conversa sobre o que está sendo tematizado. E em alguns no início, não sei se todos fizeram registro, mas que eles colocaram no papel, ou registraram o que eles conversaram em sala de aula. Não sei...

Professor 3: Todo mundo tende [tratando sobre o mapeamento] a trazer, como estas práticas acontecem no seu local de origem. De diferentes formas, vídeo, ou trazendo as pessoas, mas não sei se em todos. Mas na maioria que eu vi aqui todos querem mostrar como acontece em seu local de origem. Isso é uma coisa que aproxima todos os trabalhos aqui.
\end{abstract}

Notamos que as escritas curriculares têm começado sempre pelo mapeamento, primeiro abordando questões mais gerais sobre a escola e o que os alunos sabem ou já estudaram em relação às práticas corporais, depois utilizando estas informações para definir a prática corporal a ser tematizada. Ainda neste início, os mapeamentos ficam cada vez mais específicos, ou seja, mapeiam-se os conhecimentos dos alunos sobre a brincadeira, dança, luta, ginástica ou esporte selecionados. Em seguida, as escritas curriculares partem para a vivência, o que costuma ocorrer em momentos muito semelhantes, após uma, duas, três ou quatro aulas dedicadas ao mapeamento.

Professor 1: O que também deu para perceber é que a maioria parte para a vivência em um momento parecido. Né? Aí fazem uma discussão no início sobre o tema, aí logo depois de duas descrições, a maioria aqui, vem a vivencia sobre o tema. Isso elas se aproximam bastante.

Professor 1: Eu acho que o que aproxima aí é como, como são feitas. Porque a maioria está como mapeamento, após isso algumas vivências, aí após isso alguns vídeos. Né? A maioria está assim...

Prosseguindo com as ações didáticas, constatamos que os professores e professoras organizam atividades de aprofundamento e ampliação frequentemente interligadas, ou seja, algumas vezes são desenvolvidas na mesma aula. Outras 


\section{Usin ElturahaO}

DOI: $10.5902 / 1984644433532$

associações entre os procedimentos são bastante comuns, como aulas em que incidem atividades de mapeamento e ampliação, ressignificação e aprofundamento, ressignificação e ampliação, mapeamento e registro, aprofundamento e registro, entre outras.

Professor 3: A gente está conferindo aqui. Mas uma coisa que aparece nos trabalhos é a construção de apresentações ou de textos coletivos, coisas que finalizam o trabalho.

Professor 5: Acho que evidencia, alguma prática que evidencia a ressignificação que foi feita. Sabe de uma atividade que... você objetivamente vê o que foi feito. O percurso aí...

Professor 3: Aqui quase todo mundo teve registro. Um registro final. Por exemplo um portfólio, um vídeo, um texto, uma coreografia... só eu que não fiz.

Professor 5: [...]. Aparece muito forte estas palavras assim: Socialização de pesquisa, discussão, diálogo, ressignificações, vídeo, prática. Tô fazendo de uma forma mais marcada.

Observamos que os procedimentos do currículo cultural são traduzidos de forma mais "literal" e estruturada. É importante destacar que este aspecto não se configura como defeito ou algo ruim. Isso porque, enquanto parte da estrutura e da função social da escola contemporânea, a Educação Física cultural requer a realização de atividades de ensino que promovam o agenciamento dos sujeitos da educação de uma forma bastante peculiar. Uma vez dentro da escola, o componente possui responsabilidades sociais ligadas à modernidade, que o impedem de tornar-se um fazer qualquer.

Ao contrário do que se possa pensar, a "escrita-currículo" não deve ser entendida como um laissez-faire ou, como falaciou Chiquito (2007), um currículo marginal, anárquico, que não segue regras, porque não tem nenhuma. Afirmamos, com base na pesquisa realizada, que a "escrita-currículo" não pode ser criada apenas à mercê das intencionalidades, desejos e vontades do professor. Isso porque qualquer tipo de trabalho pedagógico não se desvincula da função social da escola, dos objetivos e finalidades da Educação Física, do Projeto Político Pedagógico e do Regimento Geral da unidade escolar, bem como da legislação educacional.

Mais do que opções pedagógicas, entendemos que os procedimentos didáticometodológicos são eles próprios constituintes da perspectiva cultural, e que sem esses constructos não existe a referida proposta. É importante, também, compreendêlos como atividades de ensino que caracterizam o processo educacional. O que não 


\section{$\sim$

DOI: $10.5902 / 1984644433532$

significa que os professores e professoras que buscam inspirar suas ações didáticas na perspectiva cultural da Educação Física devam seguir a mesma organização.

Pelo fato de uma proposta desse tipo não poder ser sistematizada de maneira universal, visto que depende intimamente daquilo que possa vir a ocorrer durante o processo educativo no qual o método de ensino é construído, somente a partir do conhecimento da realidade (grupo de alunos e comunidade onde vivem) quando se estabelece um contato mais íntimo com os seus saberes é que o método de ensino efetivamente se configura. Nesta direção, o método sugerido para uma abordagem cultural de Educação Física não comporta, em sua rotina, os tradicionais elementos da pedagogia tecnicista: semanários ou cronogramas de aula. Isso decorre do fator do improviso, e não de uma aula improvisada, nem mesmo do laissez-faire. (NEIRA; NUNES 2006, p. 240).

Já a territorialização dos princípios curriculares na "escrita-currículo" ocorre de forma heterogênea e dispersa, ou seja, operando mais como uma desterritorialização. Isso porque, ao invés se serem vistos diretamente na escrita curricular, os princípios parecem incidir diretamente nos professores e professoras.

Professor 2: No momento que eu vou artistar alguma coisa, eu particularmente sempre acabo pensando em um deles [princípios]. A partir destas coisas que a gente está conversando, o tempo que a gente está com as turmas, se é uma escola nova, dos trabalhos que a gente já fez etc.

Professor 1: Eu estou pensando que nós somos influenciados por estes princípios né? Nós os temos em nossas ações didáticas. Aí, em certos momentos pode ser que há a explosão de um deles de acordo com o que aconteça nas situações de aula. Pode ser que todos estejam nos rondando. Ou estejam rondando as aulas ali, e pode ser que em alguns momentos, ou com uma fala, ou com um posicionamento, ou como uma ação da escola com os alunos, ou com relação do que aconteça no bairro com um dos estudantes. Pode ser que um deles se sobreponha aos outros. Mas eu tento sempre estar influenciado. Não influenciado, mas... parece que isto está dentro de mim. Mas que sempre isso esteja presente. Mas que em alguns momentos, um deles possa rachar ou aparecer.

Como vemos, os professores afirmam que estes "influenciaram" os sujeitos. Primeiro, estes enunciados promoveram certos efeitos nos indivíduos, "isto está dentro de mim" (PROFESSOR 1), "estejam nos rondando" (PROFESSOR 1) e "pensando em um deles" (PROFESSOR 2), só depois, e como já dissemos, de maneira implícita, se territorializaram no currículo cultural.

Em outras palavras, os enunciados pedagógicos do currículo cultural que tratam sobre os princípios produzem efeitos indiretos na "escrita-currículo" e diretos nos 


\section{Usism Ellloahá}

DOI: $10.5902 / 1984644433532$

docentes, algo como transformações incorpóreas ${ }^{7}$. (BONETTO, 2016)

$\mathrm{Na}$ concepção filosófica em questão, podemos afirmar que os enunciados referentes aos princípios pedagógicos moveram agenciamentos flexíveis, por vezes desterritorializantes e sensíveis aos acontecimentos envolvidos no processo de criação de um currículo. Por isso, se constituem como linhas moleculares. Pelo exposto, devemos considerar que Deleuze e Guattari aderem à noção de Foucault (2009), de que a linguagem não se reduz a meramente representar os objetos, mas tem o poder de constituí-los, de modo que todos podem transformar de forma diferente o mesmo objeto, pelo poder imanente da linguagem em palavras de ordem. Tais transformações só acontecem no incorpóreo, ou seja, não se concretizam no mundo palpável. Por isso, como afirma Silva (2000), os princípios curriculares precisam ser entendidos como princípios ético-políticos.

Por fim, é possível afirmar que a força mais flexível que produz as diferenças nas ações didáticas que caracterizam esta perspectiva curricular é a grande consideração dos agenciamentos maquínicos (encontros entre professor, a cultura patrimonial da comunidade, o que os estudantes têm de experiência em relação às corporais, etc.), em especial, as falas dos estudantes no momento da aula.

Professor 1: Mas olha que legal então, talvez eu esteja me equivocando, mas um momento de contingência, um momento de problema te colocou a trazer os procedimentos de maneira diferente.

Professor 3: Um problema de contingência? Como assim? Não entendi.

Professor 1: Em relação à sua escola. Por um problema que você viveu com eles. Por conta das crianças.

Entretanto, se levarmos em consideração somente a comanda das aulas, é possível dizer que a "escrita-currículo" está sendo elaborada seguindo pari passu, sobretudo quando o referencial é a utilização dos procedimentos didáticos. Tal fenômeno nos alerta para uma certa sequência didática ou fórmula de se elaborar o currículo cultural. Isso foi observado a partir das linhas de força do tipo dura, estável

\footnotetext{
7 Entendemos aqui que as chamadas "transformações incorpóreas" ilustram o próprio poder da linguagem, ou seja, são as transformações instantâneas e imediatas provocadas pelo enunciado que a exprime e do efeito que ele produz.
} 


\section{Fism

DOI: $10.5902 / 1984644433532$

e representacional procedimentos pedagógicos propostos na teorização do currículo cultural. Além disso, deduzimos que pode ser fruto de certa desatenção dos docentes em relação aos agenciamentos maquínicos, já descritos aqui como responsáveis por produzir diferentes práticas curriculares.

Um exemplo desta desatenção pode ser dado quando se analisam os relatos de prática que abordaram as brincadeiras populares, mas em escolas diferentes, com comunidades distintas. Por que professores e professoras insistem em entrevistar e vivenciar as brincadeiras que os pais, familiares e responsáveis dos estudantes fizeram quando crianças? Por que depois de vivenciá-las solicitam que as modifiquem? Será que os discursos circulantes nas aulas conduzem à tematização dessas práticas corporais sempre na mesma direção? Não é provável que diante de outras inúmeras falas e participações, estejam desatentos às várias possibilidades de tematização e, por isso, sigam fórmulas antigas e conceitualmente incoerentes com a proposta como as do "resgate de brincadeiras tradicionais"?

\section{“Escrita-currículo": o que ela pode...}

Na direção contrária do que foi observado sobre a criação da "escrita-currículo", especialmente quando nos referimos aos procedimentos didáticos, na Educação Física culturalmente orientada ela não pode ocorrer apenas como um conjunto exaustivo de técnicas empregadas automaticamente.

O educador ou a educadora não são uma fonte originária, racional, produtora do novo, muito menos aplicador/a de um conjunto de enunciados aos quais se submete e se contenta simplesmente em replicar. Ele/a atua dentro dos agenciamentos, como mais uma dentre outras forças que se engendram na elaboração da "escrita-currículo".

No quesito linhas de força, vimos que a "escrita-currículo" não pode ser apenas constituída de linhas de fuga, pois, por possuir linhas duras, perde-se em intensidade e objetividade. Mapeamos que neste entrecruzar de linhas, a escrita curricular é, sim, repleta de linhas molares, tais como as leis educacionais, as regras e normas do 


\section{Usism Eullathá}

DOI: $10.5902 / 1984644433532$

regimento escolar, o Projeto Político Pedagógico, a concepção cultural e seus procedimentos didáticos. Mas, também se abre a agenciamentos moleculares: a cultura dos alunos, seus desejos, atitudes, falas, as disposições espaciais, temporais e os princípios curriculares.

O caráter efêmero das linhas de fuga inviabiliza a sua territorialização em enunciados pedagógicos. Elas passam pela "escrita-currículo" como acontecimentos e agenciamentos inesperados, subversivos e criadores. Exemplo disso foi o trabalho realizado por uma professora quase que integralmente baseado em vivências na rua da escola, mesmo e porque, a instituição não possui quadra nem outro espaço que a tradição do componente chamaria de "adequado" para a realização das atividades.

As diferenciações eclodem não como proposições criativas de um sujeito racional, consciente e centrado, mas como alguém que, sensível aos acontecimentos, considera-os dentro dos agenciamentos chamados aulas, conferindo-Ihes pequenas disruptivas.

Como já destacado, nesta concepção, a produção da "escrita-currículo" depende dos questionamentos e interesses surgidos a partir da tematização das práticas corporais e problematização das representações sobre elas e seus sujeitos, que circulam na sociedade. Atentos e desejando tais agenciamentos, os professores e professoras sensíveis às linhas de força flexíveis, fazem da "escrita-currículo" um acontecimento sempre traduzido, continuamente atravessado por vetores e diferentes sentidos que atribuem aos enunciados pedagógicos. A "escrita-currículo" se singulariza quando os docentes se permitem influenciar pelos enunciados inesperados emitidos pelos estudantes. Ou seja, ela se torna diferente, distinta, especial, rara e única. Mas, essa unicidade só existe se a escrita-currículo for tomada como um rizoma, ou seja, aberta para conexões (não tem início nem fim, mas meio), heterogênea, múltipla (sem unidades e definições territorializantes), sem eixos estruturais, pois promove uma ruptura a-significante, cartográfica (pois funciona como um mapa) aberta, conectável, desmontável, reversível e, por isso, impossível de ser decalcada ou copiada. 


\section{工保W \\ ISSN: 1984-6444

DOI: $10.5902 / 1984644433532$

É importante que se tenha claro que não se trata de propormos um método deleuze-guattariano de se fazer currículo, um currículo-rizoma ou currículo-mapa ${ }^{8}$. Dizer que uma coisa pode e deve ser feita rizomaticamente está longe de ser um formato fechado. Por si só, o rizoma e o mapa são um não-formato, são abertura para infinitas virtualidades.

Pode, portanto, a "escrita-currículo" se tornar uma verdadeira experiência, agenciada, contingenciada, complexa, vetorizada, micropolitizada, provisória e efêmera no espaço-tempo escolar. Isso mesmo! Uma experiência, e não um projeto. Porque projeto tem início, meio e fim, e na experiência o que vale é o meio.

\section{Referências}

AGAMBEN, Giorgio. A imanência Absoluta. In: ALLIEZ, É. (Org.). Gilles Deleuze: uma Vida Filosófica. São Paulo: Ed. 34, 2000.

BARBOUR, Rosaline. Grupos focais. Porto Alegre: Artmed, 2009.

BIANCO, Giorgio. Otimismo, Pessimismo, Criação: Pedagogia do Conceito e Resistência. Educ. Soc. Campinas, vol. 26, n. 93, set./dez. 2005.

BONETTO, Pedro Xavier Russo. A "escrita-currículo" da perspectiva cultural de Educação Física: entre aproximações, diferenciações, laissez-faire e fórmula. 2016. 250f. Dissertação (Mestrado em Educação) - Faculdade de Educação, Universidade de São Paulo, São Paulo, 2016.

CALLEJO GALLEGO, Javier. El grupo de discusión: introducción a una práctica de investigación. Barcelona: Editorial Ariel. 2001.

CHIQUITO, Ricardo Santos. Planejamento de Ensino: Formas de Ver e Maneiras de Dizer a Política Curricular. 2007. 161f. Dissertação (Mestrado em Educação). Pontifica Universidade Católica do Paraná. Paraná: PUCPR, 2007.

CORAZZA, Sandra Mara. Artistagens: filosofia da diferença e educação. Belo Horizonte: Autêntica, 2006.

CORAZZA, Sandra Mara. Notas. In: HEUSER, E. M. D. (Org.) Caderno de notas 1: projeto, notas \& ressonâncias. Cuiabá: EdUFMT, 2011.

\footnotetext{
${ }^{8}$ Seria absolutamente contraditória a elaboração de propostas curriculares, métodos de ensino e concepções pedagógicas que se filiam ao pensamento pós-estruturalista. Como o próprio termo sugere, 0 intuito não é criticar um modelo e colocar outro no lugar. O que se espera são inspirações e contribuições pontuais e contextualizadas.
} 


\section{F WFM \\ ISSN: 1984-6444 \\ ElturahaO}

DOI: $10.5902 / 1984644433532$

CORAZZA, Sandra Mara. Didaticário de criação: aula cheia, antes da aula. In: XVI ENDIPE: Encontro Nacional de Didática e Práticas de Ensino. Campinas, FE/UNICAMP. SP: 23 a 26 de julho de 2012.

CORAZZA, Sandra Mara. O que se transcria em educação? Porto Alegre: UFRGS; Doisa, 2013.

CORAZZA, Sandra Mara. Didática da tradução, transcriação do currículo (uma escrileitura da diferença). Pro-Posições, Campinas, v. 26, n. 1 (76), p. 105-122, jan./abr. 2015.

DELEUZE, Gilles. Carta a um crítico severo. In: Conversações: 1972-1990. Rio de Janeiro. Ed. 34, 1992b, p. 11-22.

DELEUZE, Gilles; GUATTARI. Félix. Mil platôs: Capitalismo e esquizofrenia. Vol. 5. Rio de Janeiro: Editora 34, 1997b.

DELEUZE, Gilles; PARNET, Claire. Diálogos. São Paulo: Escuta, 1998.

DIAS, Sousa. Partir, evadir-se, traçar uma linha: Deleuze e a literatura. Educação, Porto Alegre, ano XXX, n. 2, 62, maio/ago. 2007.

FOUCAULT, Michel. A arqueologia do saber. Rio de Janeiro: Forense Universitária, 2009.

GUTIÉRREZ BRITO, Jesús. Consignas para el despegue de un grupo de discusión: un modelo de presentación. Empiria: Revista de Metodología de Ciencias Sociales, Madri, n.2, p. 153-166, jan. 1999.

IBÁÑEZ, Jesús. Más allá de la sociología. El grupo de discusión: teoría y crítica (5a ed.) Madrid: Sieglo Veintiuno Editores, 2003.

IBÁÑEZ, Jesús. Como se realiza una investigación mediante grupo de discusión? In: M. G. Ferrando, J. Ibáñez, \& F. Alvira. El análisis de la realidad social: métodos y técnicas de investigación (3a ed.). Madrid: Alianza Editorial, 2010.

NEIRA, Marcos Garcia. Ensino de Educação Física. São Paulo: Thomson Learning, 2007.

NEIRA, Marcos Garcia. Educação Física. São Paulo: Blucher, 2011.

NEIRA, Marcos Garcia. Educação Física cultural: inspiração e prática pedagógica. Jundiaí: Paco, 2018. 


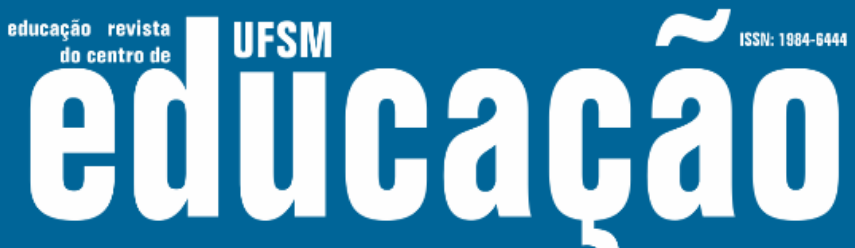

DOI: $10.5902 / 1984644433532$

NEIRA, Marcos Garcia; NUNES, Mário Luiz Ferrari. Educação Física, currículo e cultura. São Paulo: Phorte, 2009.

PAULO-BENATTE, Antonio. Deleuze e a política da literatura: algumas observações. Uniletras. Ponta Grossa, v. 34, n. 1, p. 91-96, jan./jun. 2012.

SILVA, Tomaz Tadeu (Org.). Alienígenas na sala de aula: uma introdução aos estudos culturais em educação. Rio de Janeiro: Vozes, 1995.

SILVA, Tomaz Tadeu. A produção social da identidade e da diferença. In: Identidade e diferença: a perspectiva dos Estudos Culturais. Petrópolis: Vozes, 2000, p. 73-102.

SOULIÉ, Charles. A pedagogia carismática de Gilles Deleuze na Universidade de Vincennes. Revista Linhas. Florianópolis, v. 16, n. 32, p. 286 - 314, set./dez. 2015.

WELLER, Wivian. Grupos de discussão na pesquisa com adolescentes e jovens: aportes teórico-metodológicos e análise de uma experiência com o método. Educação e Pesquisa, São Paulo, v. 32, n. 2, p. 241-260, maio/ago. 2006.

ZOURABICHVILI, François. O Vocabulário de Deleuze. Rio de Janeiro, 2004.

\section{Correspondência}

Pedro Xavier Russo Bonetto - Faculdade de Educação da Universidade de São Paulo. Av. da Universidade, 308, Butantã. CEP: 05508-040. São Paulo, São Paulo, Brasil.

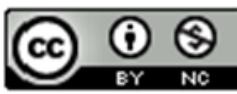

Th is work is licensed under a Creative Commons Attribution-NonCommercial 4.0 International (CC BY-NC 4.0) 